\title{
Infusion-Related Reaction
}

National Cancer Institute

\section{Source}

National Cancer Institute. Infusion-Related Reaction. NCI Thesaurus. Code C78361.

A reaction to the infusion of pharmacological or biological substances. Symptoms may appear within minutes to hours following the infusion and may include pruritus, flushing, swelling, dyspnea, bronchospasm, and hypotension. 